\title{
CARBON COATED (CARBONOUS) CATALYST IN EBULLATED BED REACTOR FOR PRODUCTION OF OXYGENATED CHEMICALS FROM SYNGAS/CO
}

\author{
Support of Advanced Fuel Research Program
}

DOE Contract Number: DE-FG26-99FT40681

DOE Project Manager : Donald Krastman

DOE Product Manager: Richard Noceti

Contract Specialist: Cynthia Mitchell

\section{Second Annual Report}

(October 1, 2000 - September 30, 2001)

Prepared for

U.S. Department of Energy

National Energy Technology Laboratory

Prepared by

Hydrocarbon Technologies, Inc.

Lawrenceville, New Jersey 08648

October 26, 2001 


\title{
CARBON COATED (CARBONOUS) CATALYST IN EBULLATED BED REACTOR FOR PRODUCTION OF OXYGENATED CHEMICALS FROM SYNGAS/CO ${ }_{2}$
}

\author{
SECOND ANNUAL REPORT
}

\section{PROJECT SUMMARY}

This report summarizes the work accomplished in the second year (October, 2000 to September, 2001) of the three year R\&D project under DOE's Support of Advanced Fuel Research program, Contract No. DE-FG26-99FT40681.

This R\&D program is concerned with the modification on the mechanical strength of the catalyst extrudates using HTI carbon-coated catalyst technology so that the ebullated-bed technology can be utilized to produce valuable oxygenated chemicals from syngas $/ \mathrm{CO}_{2}$ efficiently and economically. Exothermic chemical reactions benefit from the temperature control and freedom from catalyst fouling provided by the ebullated bed reactor technology.

In the first year of the $\mathrm{R} \& \mathrm{D}$ program, procedures for carbonous extrusion and carbon coating of the SOTA zinc-chromite catalyst and the Advanced $\mathrm{K}-\mathrm{Mn}$ promoted $\mathrm{ZrO}_{2}$ catalyst were developed with success.

Majority of the work accomplished in the second year of the program are in the following areas:

\section{Task I \& II: Catalyst Preparation and Characterization}

Carbonous extrusion and carbon coating procedures were developed for SOTA low-temperature copper-zinc-chromite catalyst and $\mathrm{K}-\mathrm{Mn}$ promoted $\mathrm{ZrO}_{2}$ Advanced catalyst using partially polymerized furfuryl alcohol. The carbon-coated extrudates had sufficient crush strength and surface area for ebullated bed operation. Carbon-coated zinc-chromite and copper-zinc-chromite catalyst extrudates were prepared for catalyst activity test runs. The carbon-coated SOTA and advanced catalyst extrudates were analyzed by SEM/EDS and XPS studies.

Task III: Experimental Runs For Catalyst Activity Studies

Three experimental runs were conducted with carbon-coated catalysts in a two-stage RobinsonMahoney autoclave reactor system with catalyst basket using decalin and tetraethylene glycol as the liquid medium at 1,500 psig pressure. The first run was with carbon-coated cesium promoted zinc-chromite catalyst. The second and third runs used carbon-coated cesium promoted copperzinc-chromite catalyst extrudates. Depending upon operating conditions, these runs produced methanol, higher alcohols, and other oxygenates. In the last period of the third run, increasing operating pressure to $1,700 \mathrm{psig}$ resulted in major increase in higher alcohols in quantity and quality. In most cases, the catalyst attrition was low. Ebullated bed experimental runs at 2,000 psig pressure using carbon-coated SOTA and Advanced catalysts are recommended. 


\section{Task IV \& VI: Large Scale Process and Cost For Carbon Coated Catalyst Production}

The key step of carbonous extrusion was developed as a fast process. A large scale process was proposed for production of carbon-coated catalyst extrudates from catalyst powder using partially polymerized furfuryl alcohol. A cost estimation was carried out for the carbonous extrusion and carbon-coating component in the production of carbon-coated copper-zinc-chromite catalyst extrudates. The low cost of carbon coating makes the carbon-coated catalysts highly competitive in the market of catalyst extrudates.

In order to determine the commercial potential of the carbon-coated catalyst in ebullated bed reactor operation, the following incomplete work in the project is planned:

i. Actual ebullated bed bench-scale runs using carbon-coated SOTA and Advanced catalysts at $\geq 2,000$ psig pressure using syngas.

ii. Economic assessment of the overall process and technology of carbon-coated catalyst in ebullated bed reactor operation. 


\section{TABLE OF CONTENTS}

Number

Page

$\begin{array}{ll}\text { INTRODUCTION } & 1\end{array}$

$\begin{array}{ll}\text { OBJECTIVE } & 1\end{array}$

$\begin{array}{ll}\text { WORK PLAN } & 1\end{array}$

WORK ACCOMPLISHED IN THE SECOND YEAR OF THE PROGRAM 2

Task I \& II: Catalyst Preparation and Characterization 2

1) Carbon-Coated Cesium-Copper-Zinc-Chromite SOTA Catalyst 2

2) K-Mn Promoted $\mathrm{ZrO}_{2}$ Advanced Catalyst 4

3) SEM/EDS and XPS Analyses of Carbonous Catalyst Extrudates 5

Task III: Experimental Run For Catalyst Activity Studies $\quad 5$

1) Catalyst Activity Test Run 245-59 With Carbon-Coated SOTA Cesium-Promoted Zinc-Chromite Catalyst 5

2) Microautoclave Test Runs For Liquid Medium Stability Studies 14

3) Catalyst Activity Test Run 245-60 With Carbon-Coated SOTA Cesium-Promoted Copper-Zinc-Chromite Catalyst 15

4) Catalyst Activity Test Run 245-64 With Carbon-Coated SOTA

Task IV: Large Scale Process For Carbon-Coated Catalyst Production 26

$\begin{array}{ll}\text { Task VI: Cost Estimation } & 28\end{array}$

$\begin{array}{ll}\text { CONCLUSION } & 30\end{array}$

FURTHER WORK PLANNED $\quad 30$ 


\section{CARBON COATED CATALYST IN EBULLATED BED REACTOR FOR PRODUCTION OF OXYGENATED CHEMICALS FROM SYNGAS/CO}

\section{INTRODUCTION}

There are a number of exothermic chemical reactions which might benefit from the temperature control and freedom from catalyst fouling provided by the ebullated bed reactor technology. A particularly promising area is production of oxygenated chemicals, such as alcohols and ethers, from synthesis gas, which can be economically produced from coal or biomass. The ebullated bed operation requires that the small-diameter $(\sim 1 / 32 ")$ catalyst particles have enough mechanical strength to avoid loss by attrition. However, all of the State Of The Art (SOTA) catalysts and advanced catalysts for the purpose are low in mechanical strength. The patented carbon-coated catalyst technology developed in our laboratory converts catalyst particles with low mechanical strength to strong catalysts suitable for ebullated bed application.

This R\&D program is concerned with the modification on the mechanical strength of the SOTA and advanced catalysts so that the ebullated bed technology can be utilized to produce valuable oxygenated chemicals from syngas/ $\mathrm{CO}_{2}$ efficiently and economically.

\section{OBJECTIVE}

The objective of this R\&D program is to study the technical and economic feasibility of selective production of high-value oxygenated chemicals from synthesis gas and $\mathrm{CO}_{2}$ mixed feed in an ebullated bed reactor using carbon-coated catalyst particles.

\section{WORK PLAN}

The following tasks are to be performed in the three years program to attain the objectives of the $\mathrm{R} \& \mathrm{D}$ program.

Task I: Preparation of Carbon-Coated Catalysts

Task II: Characterization of Catalysts

Task III: Evaluation of Catalyst Activities

Task IV: Large Scale Production of Optimum Catalysts

Task V: Bench Scale Ebullated Bed Evaluation of the Optimum Catalyst

Task VI: Economic Assessment of the Carbon-Coated Catalyst--Ebullated Bed Technology

Task VII: Preparation of Final Report 


\section{WORK ACCOMPLISHED IN THE SECOND YEAR OF THE PROGRAM}

In the first year of the R\&D program, procedures for carbonous extrusion and carbon coating of (1) SOTA zinc-chromite catalyst and (2) K-Mn promoted $\mathrm{ZrO}_{2}$ Advanced catalyst were developed with success using partially polymerized furfuryl alcohol. The carbon-coated extrudates had sufficient attrition resistance and surface area for use in ebullated bed operation.

In the second year of the program, work has been accomplished for the Tasks I, II, III, IV and VI. Work accomplished in each of these Tasks, the results and discussion are presented in the following sections.

\section{Tasks I \& II: Catalyst Preparation and Characterization}

During a catalyst activity test Run 245-59 under Task III using carbon-coated SOTA zincchromite catalyst extrudates, it was observed that the liquid media decalin and tetra-ethylene glycol were cracking at temperatures above $700^{\circ} \mathrm{F}$. As a result, the low temperature SOTA catalyst copper-zinc-chromite $\left(\mathrm{Cu}-\mathrm{ZnO}-\mathrm{Cr}_{2} \mathrm{O}_{3}\right)$ catalyst was selected for later activity test runs. Work on preparation and characterization of carbon-coated copper-zinc-chromite catalyst extrudates was carried out.

Since the carbonous extrusion and carbon coating work on the K-Mn promoted $\mathrm{ZrO}_{2} \mathrm{Advanced}$ catalyst was limited in the first year program, further work was conducted in the second year.

SEM/EDS and XPS analyses were conducted on the carbon-coated SOTA and Advanced catalyst extrudates.

\section{1) Carbon-coated Cesium-Copper-Zinc-Chromite SOTA Catalyst}

\section{Preparation of Copper-Zinc-Chromite $\left(\mathrm{Cu}-\mathrm{ZnO}-\mathrm{Cr}_{2} \mathrm{O}_{3}\right)$ Catalyst Powder.}

The copper-zinc-chromite catalyst powder was prepared by co-precipitation of aqueous solutions of copper nitrate, zinc nitrate and chromium nitrate in a basic solution followed by heating the solution, filtering the slurry, washing, and calcining the powder. The aqueous solutions of copper nitrate, zinc nitrate and chromium nitrate were mixed in desired proportion. The resulting solution was poured slowly into an aqueous solution of $\mathrm{K}_{2} \mathrm{CO}_{3}$ and $\mathrm{KOH}$ (maintained at $\mathrm{pH}=7.9$ to 10) at $30^{\circ} \mathrm{C}$ to $35^{\circ} \mathrm{C}$ temperature with stirring. The precipitated product slurry was heated to $70^{\circ} \mathrm{C}$ and stirred for 3 hours. The product was filtered and rinsed three times with de-ionized water. The powder was dried at $100^{\circ} \mathrm{C}$ in a vacuum oven and analyzed to ensure that $\mathrm{K}$ level was <300 ppm. The powder was calcined at $325^{\circ} \mathrm{C}$ in air for 2 to 3 hours. The powder was ball milled to -200 mesh. Surface area of the catalyst powders prepared varied between 100 to $140 \mathrm{~m}^{2} / \mathrm{gm}$. 
The carbon-coated SOTA copper-zinc-chromite catalyst extrudates prepared for the Run 245-60 were heating up as they came in contact with air. As a result, the carbon coating procedure could not be properly applied. In order to avoid this problem we had to prepare the catalyst powder with less activity toward oxidation. However, we must have high surface area for high activity towards the desired reactions. Upon modification of the catalyst powder preparation procedure, the copper-zinc-chromite powder was not very active towards oxidation. The main modification was longer (30 hours) digestion time of the product slurry at $70^{\circ} \mathrm{C}$ after the precipitation reactions. The surface area of the catalyst powders prepared varied between 96 to $141 \mathrm{~m}^{2} / \mathrm{gm}$.

\section{Preparation of Carbonous Copper-Zinc-Chromite Catalyst Extrudates}

The copper-zinc-chromite catalyst powder was extruded and carbon-coated using partially polymerized furfuryl alcohol and the procedure described in detail in the First Annual Report. A laboratory scale extruder from The Bonnot Company was modified into the manual mode and fitted with piston and die for making $1 / 40 "(0.7 \mathrm{~mm})$ diameter extrudates.

Second coating of the extrudates was needed to achieve proper crush strength. Carbonization of the extrudates was conducted at $1200-1300^{\circ} \mathrm{F}$ temperatures in a flow of nitrogen for 4 hours. Partial oxidation of the carbonized extrudates was conducted at $800^{\circ} \mathrm{F}$ temperature in a flow of a mixture of nitrogen and air containing 0.5 to $1.0 \mathrm{v} \%$ oxygen for 2 hours. The catalyst extrudates were analyzed for surface area and crush strength.

Sample No.

$\mathrm{CCuZnCr}-121400$

CCsCuZnCr-71001SB

CCsCuZnr-71001SB

* Using ASTM D4179-82 method.

\section{Extrudate Diameter, mm}

0.7

0.7

\author{
*Crush \\ Strength, lb/mm
}

2.47

2.7

$\begin{gathered}\text { Surface } \\ \text { Area, } \mathbf{~ m}^{2} / \mathbf{g m}\end{gathered}$
52.6
89

\section{Cesium Doping of Copper-Zinc-Chromite Carbonous Extrudates}

Prior to impregnation with cesium compound, the zinc-chromite catalyst powder was subjected to carbonous extrusion and carbon coating procedure to prepare catalyst extrudates. The reason is that the high temperature of carbon coating procedure may deactivate the cesium component of the catalyst. Cesium doping with formate salt $\mathrm{CsOOCH}$ was effected by adding the catalyst extrudates in a nitrogen purged aqueous $\mathrm{CsOOCH}$ solution with desired concentration at $50^{\circ} \mathrm{C}$. The weight ratio of catalyst to aqueous solution was $1: 10$. The solution was then evaporated to dryness. The target cesium concentration on the catalyst was 3 mole\%. 


\section{2) K-Mn Promoted $\mathrm{ZrO}_{2}$ Advanced Catalyst.}

Potassium and $\mathrm{Mn}$ promoted $\mathrm{ZrO}_{2}$ catalyst powder was prepared by co-precipitation. Aqueous solution of $\mathrm{ZrOCl}_{2}$ and aqueous solution of $\mathrm{Mn}\left(\mathrm{NO}_{3}\right)_{2}$ were slowly and concurrently added to a $3.5 \mathrm{M}$ ammonium hydroxide solution in a container with continuous stirring at $50^{\circ} \mathrm{C}$ keeping the solution $\mathrm{pH}$ at 9 . The precipitate was filtered and washed with deionized water. The powder was dried at $120^{\circ} \mathrm{C}$ in a vacuum oven for 4 hours. The powder was calcined at $600^{\circ} \mathrm{C}$ in air for 5 hours. $\mathrm{K}_{2} \mathrm{CO}_{3}\left(2 \mathrm{w} \%\right.$ based on $\left.\mathrm{K}_{2} \mathrm{O}\right)$ was then impregnated into the powder using aqueous solution incipient impregnation procedure. The resulting powder was ball milled to -200 mesh.

\section{Preparation of Carbonous Mn and $\mathrm{K}$ Promoted $\mathrm{ZrO}_{2}$ Catalyst.}

Carbonous extrusion and carbon coating of the $\mathrm{Mn}-\mathrm{K}$ promoted $\mathrm{ZrO}_{2}$ catalyst powder were carried out using partially polymerized furfuryl alcohol with moderate degree of polymerization and the procedure developed in the first year of the program. A laboratory scale extruder from The Bonnot Company was modified into the manual mode and fitted with piston and die for making $1 / 40 "(0.7 \mathrm{~mm})$ diameter extrudates.

The partially polymerized furfuryl alcohol was prepared by adding $0.3-0.4 \mathrm{cc} \mathrm{of} \mathrm{H}_{2} \mathrm{SO}_{4}$ as catalyst into $100 \mathrm{cc}$ of furfuryl alcohol and heating at 70-80 C for 5-6 minutes with constant stirring.

Carbonous extrusion of $\mathrm{K}-\mathrm{Mn}$ promoted $\mathrm{ZrO}_{2}$ catalyst powder and subsequent carbon coating (includes second coating) of the extrudates using the partially polymerized furfuryl alcohol resulted in extrudates with sufficient crush strength and reasonable surface area as presented in the following table:

$\underline{\text { Sample }}$

$\mathrm{CKZrMnO}_{\mathrm{x}}-090800$

CKZrMnOx-091900

CKZrMnOx-092200

CKZrMnOx-092500
Extrudate

Diameter, inch

$1 / 40 "$

$1 / 40 "$

$1 / 40 "$

$1 / 40^{\prime \prime}$
Carbon, $\underline{\mathrm{w} \%}$

14.35

19.84

** Using ASTM D4179-82 method. 
Mr. John Baltrus of NETL with the permission from Dr. Anthony Cuigini and Dr. Richard P. Noceti helped us in conducting XPS and SEM/EDS analyses of two carbon-coated catalyst extrudate samples. The results can be summarized as follows:

\section{(a) Carbon-Coated SOTA Cs-Promoted Zinc Chromite Catalyst Extrudate}

The major surface elements on both the side and end of the extrudate were $\mathrm{C}, \mathrm{O}, \mathrm{Zn}, \mathrm{Cr}$, and Cs. The carbon appeared to be graphite. XPS indicated that the cross section of the extrudate contained more carbon and less zinc than those at the extrudate wall. However, the Cs concentration was uniform throughout.

The SEM images of the extrudate cross section showed that the extrudate was formed by compressing particles of $<100$ micrometer size. Individual elemental maps of the cross section showed the elemental distribution to be fairly uniform.

\section{(b) Carbon-Coated K-Mn Promoted Zirconia Advanced Catalyst Extrudate}

The major elements on the surface of the extrudate were $\mathrm{C}, \mathrm{O}$ and $\mathrm{Zr}$. The $\mathrm{Mn}$ and $\mathrm{K}$ signals were extremely weak. The carbon was present as graphite and $\mathrm{Zr}$ was present as the oxide. The $\mathrm{Zr}$ and Mn were uniformly distributed throughout the cross section. XPS and SEM/EDS results showed elevated levels of carbon at the extrudate wall.

\section{Task III: $\quad$ Experimental Run For Catalyst Activity Studies}

\section{1) Catalyst Activity Test Run 245-59 With Carbon-Coated SOTA Cesium-Promoted Zinc-Chromite Catalyst}

Catalyst activity testing was conducted in a two stage Robinson Mahoney reactor system (Unit 245) consisting of two stirred 1-liter autoclave reactors with catalyst basket. The basket had cylindrical annular space for catalyst. The catalyst basket in each reactor was initially charged with 100 gms of carbon coated, Cs-promoted zinc-chromite catalyst. Syn-gas with $\mathrm{H}_{2} / \mathrm{CO}$ ratio of 0.75 and $5 \mathrm{v} \% \mathrm{CO}_{2}$ was used as the feed gas. Decalin (b.p $374^{\circ} \mathrm{F}$ ) and later tetra-ethylene glycol (b.p. $597^{\circ} \mathrm{F}$ ) were used as the liquid medium. Stirrer speed was maintained constant at $1200 \mathrm{rpm}$.

A 120 hours of run (24 hours for each period) with two different space velocities was conducted at 1500 psig pressure, $650-700^{\circ} \mathrm{F}$ temperature in the first stage and $680-790^{\circ} \mathrm{F}$ temperature in the second stage. A sketch of the Unit 245 experimental set up is shown in Figure 1.

The catalyst activity test run 245-59 started using carbon-coated catalyst extrudates and decalin as liquid medium. The L-1157 liquid was a mixture of $85 \mathrm{w} \%$ methanol, $5 \mathrm{w} \%$ ethanol and 10 $\mathrm{w} \%$ propanol. The run was stopped at the beginning of third period due to a plug in the line between the two reactors. 
The used catalyst was toluene washed and reintroduced in the reactors for restarting the run for the rest three periods.

Because of loss of decalin and apparent cracking of decalin in the first two periods, the run was restarted using tetraethylene glycol (b.p. $597^{\circ} \mathrm{F}$ ) as the liquid medium. Although there was loss and apparent cracking of tetraethylene glycol, the remaining three periods of the run was conducted without any problem.

Table 1 and Table 2 present the operating conditions and results of the run. Results show that $\mathrm{CO}$ conversion was approximately 13-14 V\% at higher rate of feed gas (GHSV $2010 \mathrm{Liter} / \mathrm{Kg}$ Catalyst/Hr) and $30 \mathrm{~V} \%$ at lower rate of feed gas (GHSV 1005 Liter/Kg Catalyst/Hr).

The analyses of the light liquid product (0-4 stream) and heavy liquid product (0-5 stream) are presented in the tables. For the period 5B, the elemental analyses show the presence of oxygenated hydrocarbons.

The Infra-Red analyses for the liquid fractions (IBP- $185^{\circ} \mathrm{F}, 185-250^{\circ} \mathrm{F}, 250-340^{\circ} \mathrm{F}$ ) of period $245-$ 59-5B are attached. Strong peaks at 3200-3650 are due to alcohols. Strong peaks at 1050-1300 are due to alcohols and ethers. Peaks at 1340-1470 are due to alkanes. Peaks at 1610-1680 are due to alkenes. Strongest peaks are due to alcohols. Boiling point analyses show that these alcohols are mostly higher alcohols.

The spent catalysts were toluene extracted and weighed. Results showed that there was no loss of catalyst by attrition. 


\section{Table 1}

\section{Catalyst Activity Testing}

RUN 245-59

CARBON-COATED CATALYST IN EACH REACTOR: $100 \mathrm{Gm}$

\section{Period}

Reactor Pressure, psig

Reactor K-1 Temperature,

of

Reactor K-2 Temperature, $\stackrel{\circ}{\circ}$

Inlet $\mathrm{H} 2 / \mathrm{CO} / \mathrm{CO}_{2} \mathrm{GHSV}(1 / \mathrm{kg}-\mathrm{cat} / \mathrm{hr})$

L-1157 Liquid Pump Rate to K-2, Gm/Hr

Liquid Medium (Decalin) Recycle, $\mathrm{Gm} / \mathrm{Hr}$

0-4 Liquid Product, $\mathrm{Gm} / \mathrm{Hr}$

0-5 Liquid Product, $\mathrm{Gm} / \mathrm{Hr}$

CO Conversion, V\%

$\begin{array}{rrrr}\mathbf{1 A} & \text { 1B } & \text { 2A } & \text { 2B } \\ 1500 & 1500 & 1500 & 1500 \\ 730 & 730 & 715 & 650 \\ 790 & 790 & 750 & 680 \\ & & & \\ 2010 & 2010 & 2010 & 2010\end{array}$

48
$100 \quad 100$

60.4

78.5

12.95

13.45

0.65

0.65

0.26

Gaseous

Products:

0.39

$\mathrm{C}_{1}-\mathrm{C}_{3}, \mathrm{gm} / \mathrm{hr}$
$\mathrm{C}_{4}-\mathrm{C}_{7}, \mathrm{gm} / \mathrm{hr}$

0-4 Liquid Product

Analyses:

Carbon, wt\%

Hydrogen, wt \%

Oxygen (By Difference), wt\%

0-5 Liquid Product Analyses:

Carbon, wt $\%$

45.9

12.77

41.33

86.29

13.71

Oxygen (By Difference), wt\%
46.04

11.6

42.36

86.42

13.58 
Table 2

\section{Catalyst Activity Testing}

RUN 245-59

Carbon-Coated Catalyst in Each Reactor: 80 Gm

\begin{tabular}{|c|c|c|c|c|c|c|}
\hline Period & $3 A$ & $3 B$ & $4 A$ & $4 B$ & $5 A$ & $5 B$ \\
\hline Reactor Pressure, psig & 1500 & 1500 & 1500 & 1500 & 1500 & 1500 \\
\hline Reactor K-1 Temperature, ${ }^{\circ} \mathrm{F}$ & 681 & 679 & 688 & 700 & 700 & 700 \\
\hline Reactor K-2 Temperature, ${ }^{\circ} \mathrm{F}$ & 693 & 696 & 718 & 738 & 739 & 739 \\
\hline Inlet $\mathrm{H} 2 / \mathrm{CO} / \mathrm{CO}_{2} \mathrm{GHSV}(\mathrm{l} / \mathrm{kg}$-cat/hr) & 2010 & 2010 & 2010 & 2010 & 1005 & 1005 \\
\hline $\begin{array}{l}\text { L-1157 Liquid Pump Rate to K-2, } \\
\text { Gm/Hr } \\
\text { Liquid Medium (Tetraethylene } \\
\text { Glycol) Recycle, Gm/Hr }\end{array}$ & 50 & 0 & 24 & 24 & 7 & 50 \\
\hline $\begin{array}{l}\text { 0-4 Liquid Product, } \mathrm{Gm} / \mathrm{Hr} \\
0-5 \text { Liquid Product, } \mathrm{Gm} / \mathrm{Hr}\end{array}$ & $\begin{array}{l}37.8 \\
29.4\end{array}$ & $\begin{array}{l}36.9 \\
16.6\end{array}$ & $\begin{array}{r}56.4 \\
9.1\end{array}$ & $\begin{array}{r}51.9 \\
3.8\end{array}$ & $\begin{array}{r}28.5 \\
4.9\end{array}$ & $\begin{array}{r}28.4 \\
7.8\end{array}$ \\
\hline CO Conversion, V\% & & 14.26 & & 13.8 & & 30.47 \\
\hline $\begin{array}{l}\text { Gaseous Products: } \\
\qquad \begin{array}{r}\mathrm{C}_{1}-\mathrm{C}_{3}, \mathrm{gm} / \mathrm{hr} \\
\mathrm{C}_{4}-\mathrm{C}_{7}, \mathrm{gm} / \mathrm{hr}\end{array}\end{array}$ & & $\begin{array}{l}0.85 \\
1.25\end{array}$ & & $\begin{array}{l}0.75 \\
0.65\end{array}$ & & $\begin{array}{l}0.83 \\
0.58\end{array}$ \\
\hline $\begin{array}{l}\text { 0-4 Liquid Product Analyses: } \\
\text { Carbon, wt\% } \\
\text { Hydrogen, wt\% } \\
\text { Oxygen(By Difference), wt\% } \\
\text { IBP-185F, V\% } \\
185-250^{\circ} \mathrm{F}, \mathrm{V} \% \\
250^{\circ} \mathrm{F}+\mathrm{V} \%\end{array}$ & & $\begin{array}{l}49.78 \\
11.17 \\
39.05\end{array}$ & & $\begin{array}{l}50.55 \\
11.42 \\
38.03\end{array}$ & & $\begin{array}{r}52.16 \\
11.24 \\
36.6 \\
71 \\
24 \\
5\end{array}$ \\
\hline $\begin{array}{l}\text { 0-5 Liquid Product Analyses: } \\
\text { Carbon, wt } \% \\
\text { Hydrogen, wt\% } \\
\text { Oxygen (By Difference), wt\% }\end{array}$ & & $\begin{array}{l}48.93 \\
10.66 \\
40.41\end{array}$ & & $\begin{array}{l}65.23 \\
11.61 \\
23.21\end{array}$ & & $\begin{array}{l}54.78 \\
11.69 \\
33.53\end{array}$ \\
\hline $\begin{array}{l}\text { IBP-250ํF, V\% } \\
250-340^{\circ} \mathrm{F}, \mathrm{V} \% \\
340^{\circ} \mathrm{F}+, \mathrm{V} \%\end{array}$ & & & & & & $\begin{array}{r}62 \\
36 \\
2\end{array}$ \\
\hline
\end{tabular}


Figure 1

Unit-245 for Syngas to Oxygenates

(Robinson-Mahoney Reactor)

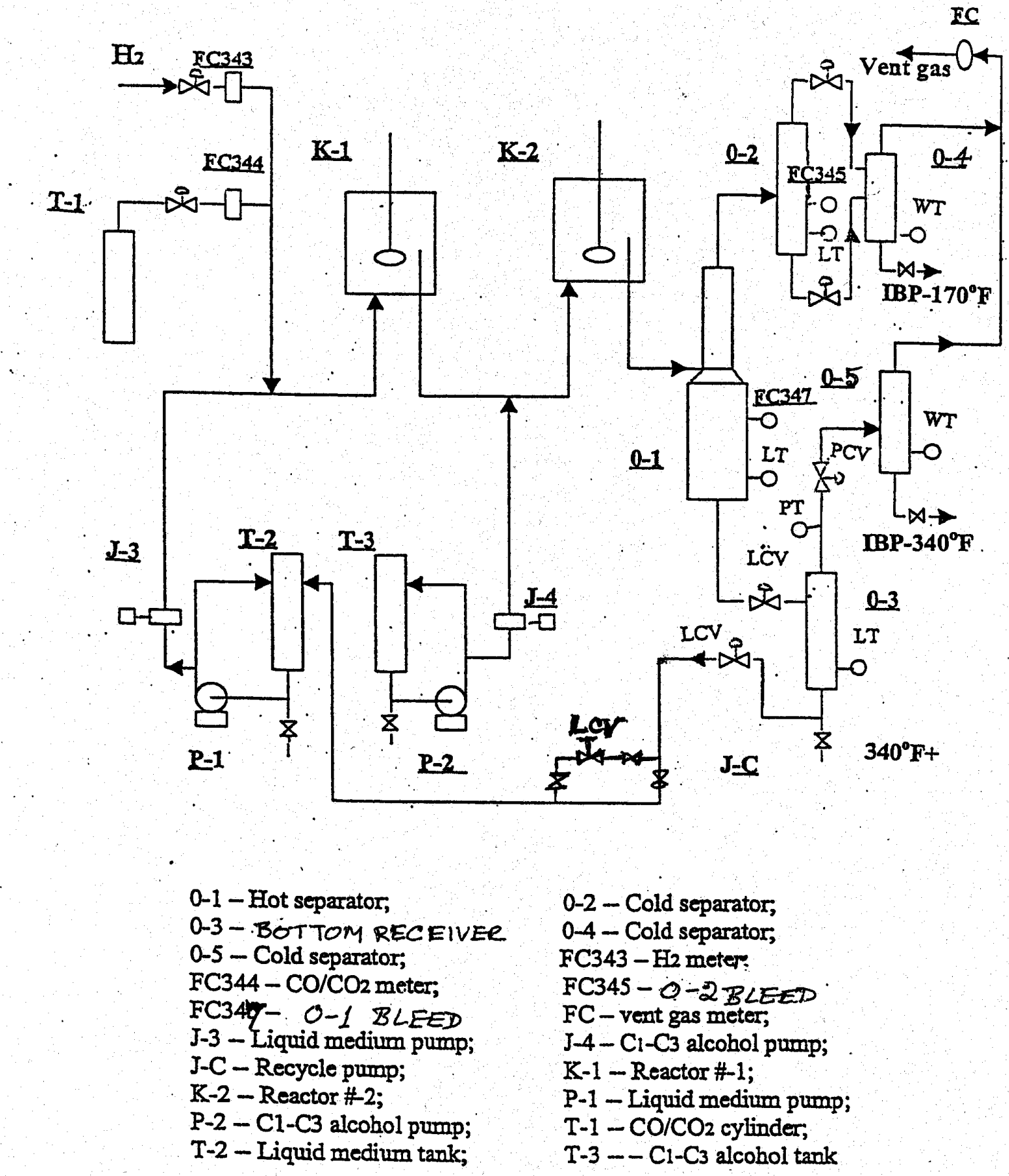




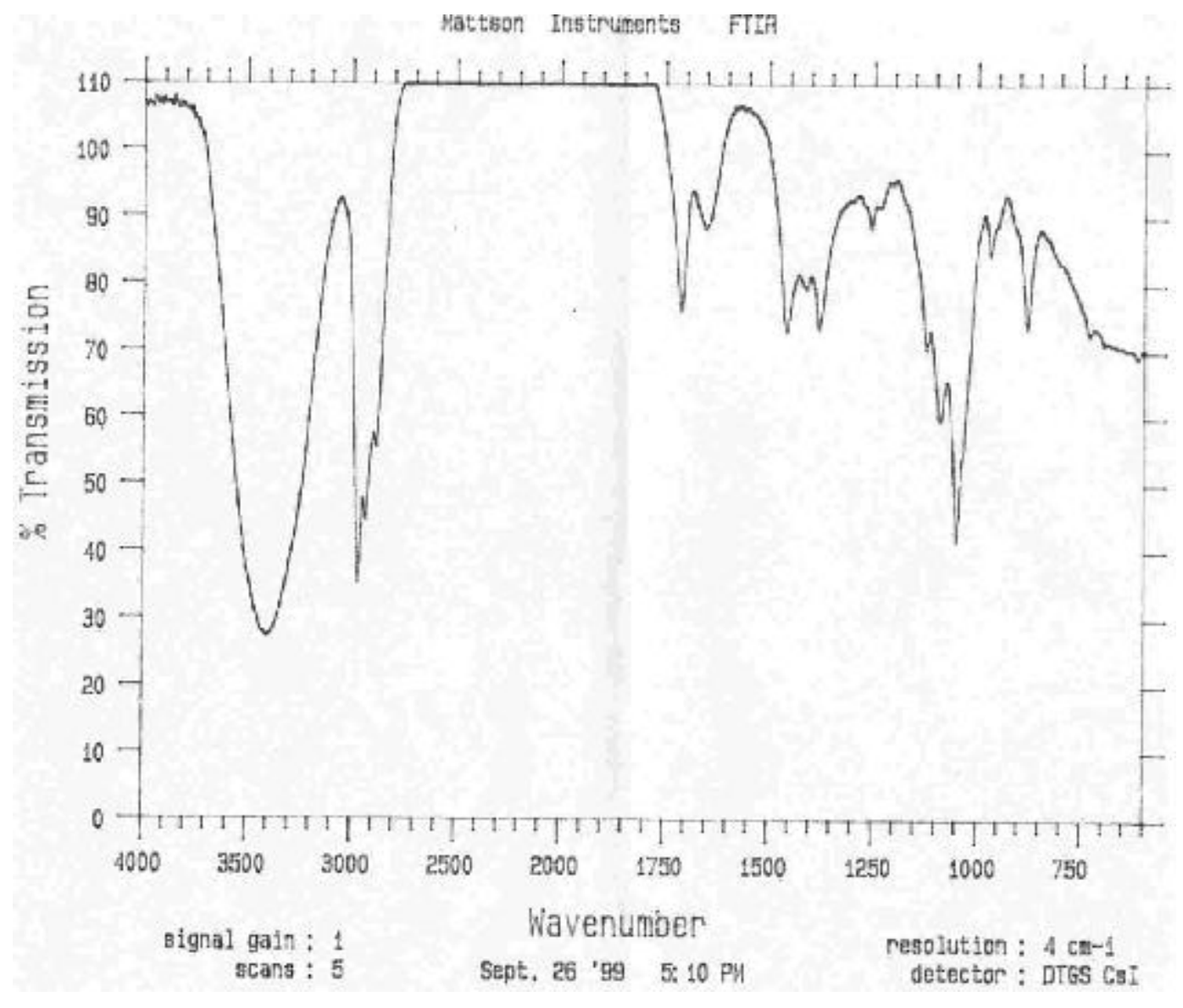

245-59-5B O-4 product Ibp-185다 


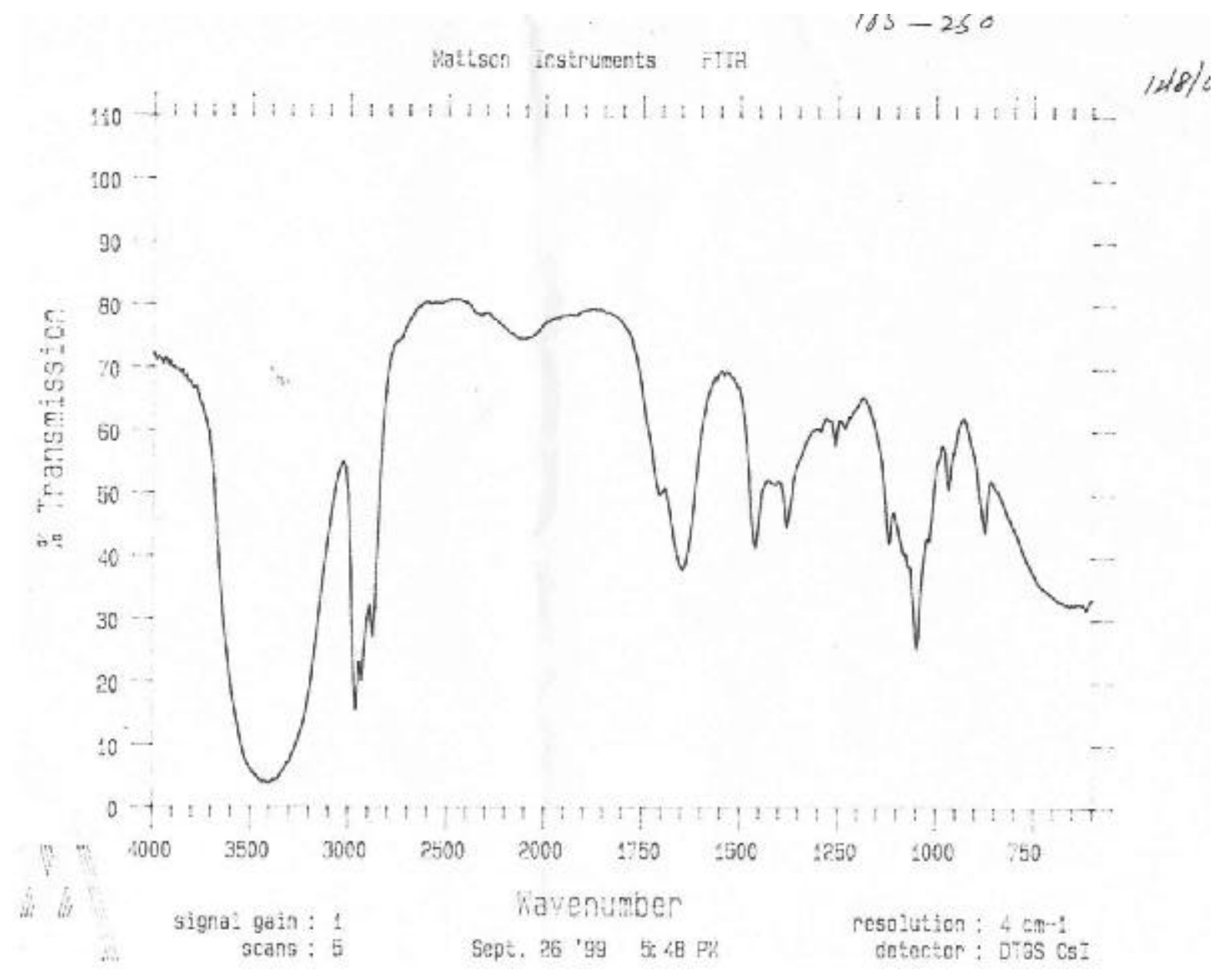

245-59-5B O-4 Product $185^{\circ} \mathrm{F}-250^{\circ} \mathrm{F}$ 


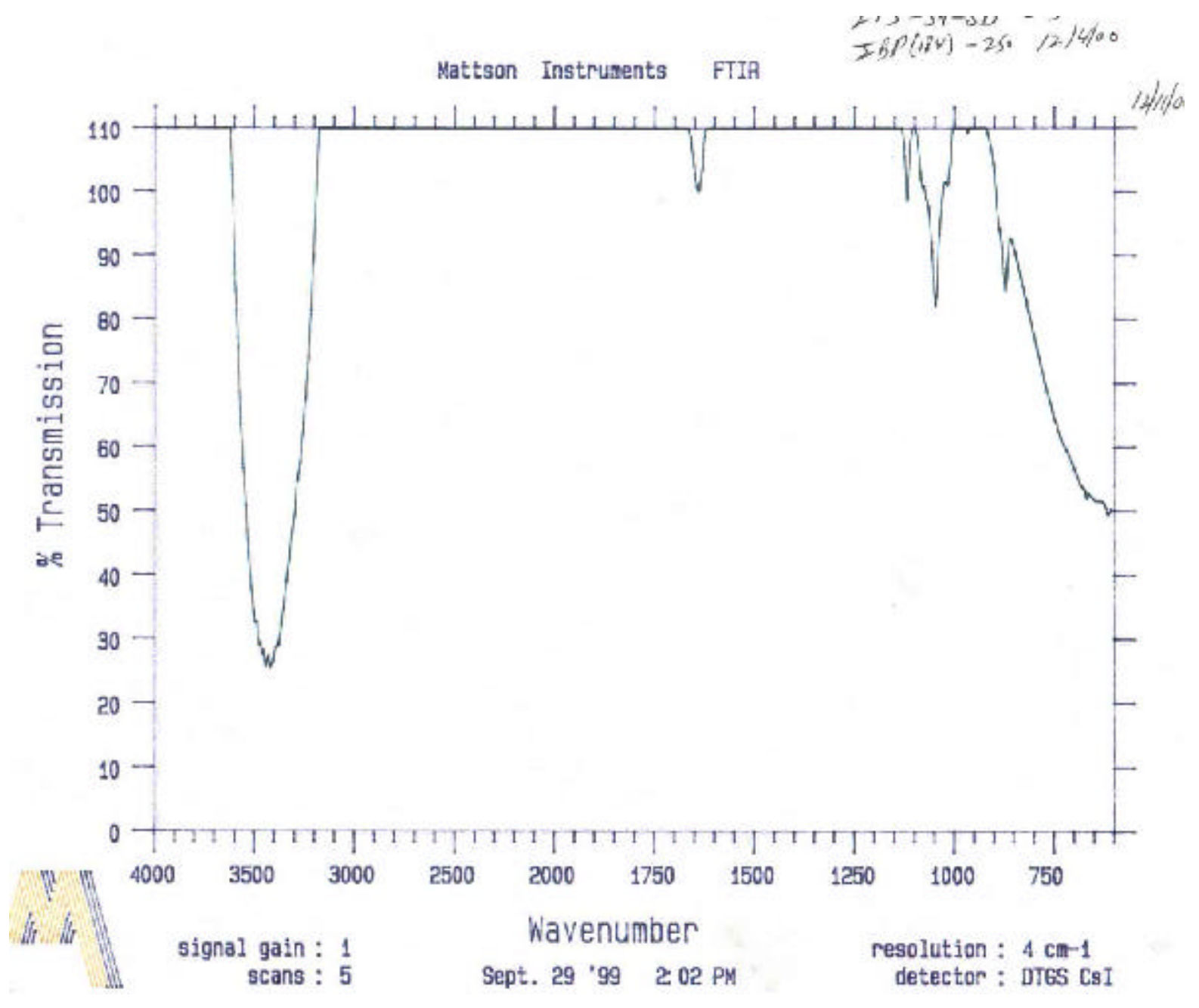

245-59-5B O-5 Product Ibp-250ํF 


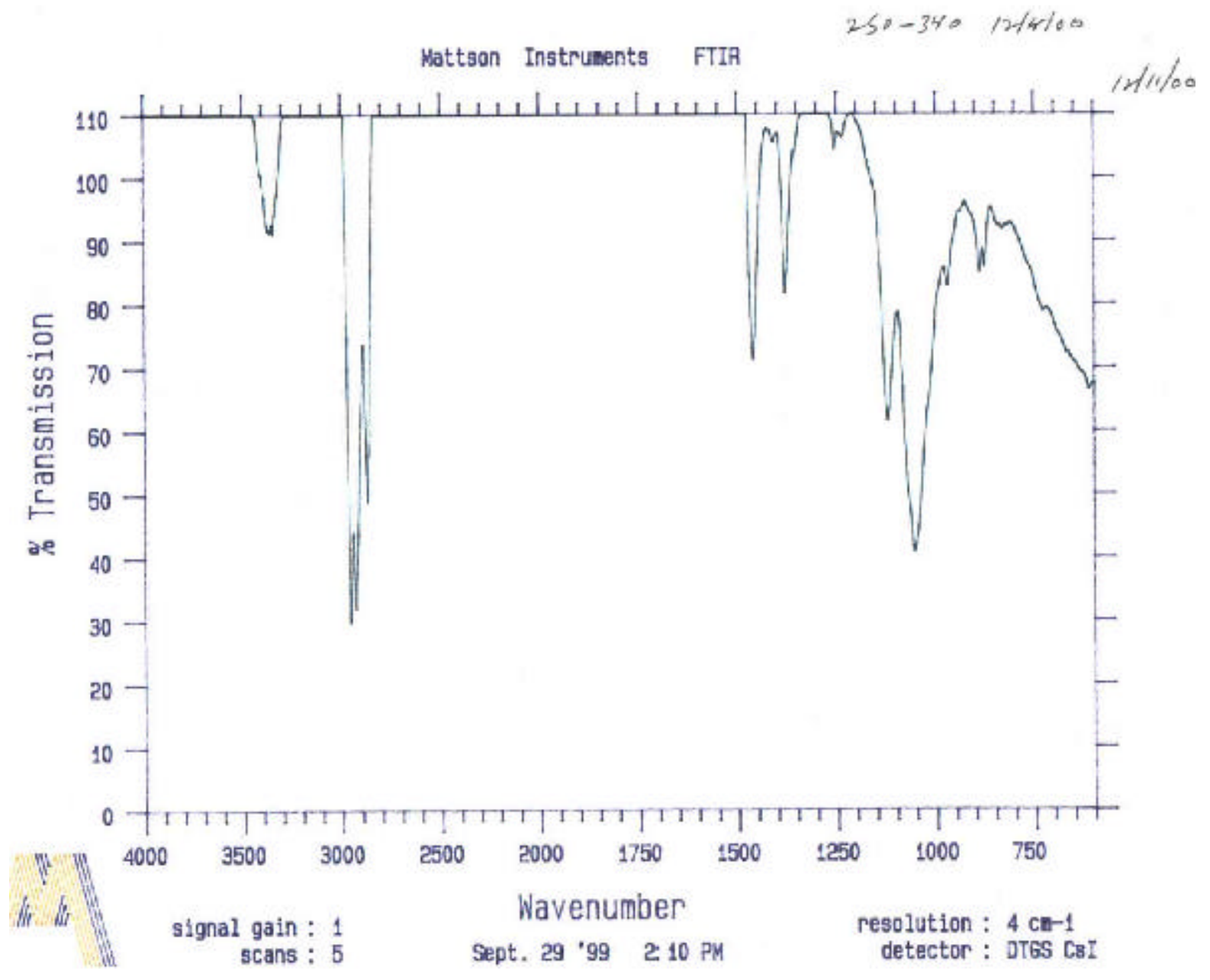

245-59-5B O-5 product $250^{\circ} \mathrm{F}-340^{\circ} \mathrm{F}$ 


\section{2) Microautoclave Test Runs For Liquid Medium Stability Studies}

In order to avoid the problem of cracking of liquid medium in the next catalyst activity test run, the following two approaches were selected:

(a) The test run was to be conducted at low temperatures by the use of carbon-coated SOTA (state of the art) low-temperature/pressure catalyst such as cesium-promoted $\mathrm{CuZnOCr}_{2} \mathrm{O}_{3}$ extrudates. Temperatures in the range of 570 to $700^{\circ} \mathrm{F}$ can be effective in the test run. This catalyst system should also be suitable for the moderate pressure ( 1400 to 1500 psig) capability available to us. Since the preparation and characterization of the catalyst extrudates more appropriately fall under Task I and Task II, the activities in these areas are described under Task I and Task II.

(b) The test run was conducted using an alternate liquid medium such as 1-methyl naphthalene with suitable boiling point of $465^{\circ} \mathrm{F}$ and more refractory to cracking due to mainly aromatic structure. However there was the possibility of cracking of the methyl group leading to undesirable naphthalene in the liquid medium.

Before conducting the catalyst activity test run, we had to test the stability of different liquid media at 650 to $800^{\circ} \mathrm{F}$ temperature range in the presence of the SOTA carbon-coated catalysts. Micro-autoclave test runs were conducted for the purpose. The following table presents the summarized data of these test runs using carbon-coated cesium promoted zinc-chromite (C-Cs$\left.\mathrm{ZnOCr}_{2} \mathrm{O}_{3}\right)$ catalyst and carbon-coated copper-zinc-chromite $\left(\mathrm{C}-\mathrm{CuZnOCr}_{2} \mathrm{O}_{3}\right)$ catalyst for two liquid media--- 1-Methyl Naphthalene and Decalin:

\section{Liquid Medium: 1-Methyl Naphthalene}

$\begin{array}{lcccc}\text { Run Duration, Minutes } & 120 & 120 & 120 & 120 \\ \text { Hydrogen Pressure, psig } & 2000 & 2000 & 2000 & 2000 \\ \text { Catalyst } & \begin{array}{c}\text { C-Cs-ZnCr } \\ \text { or } \\ \text { C-CuZnCr }\end{array} & \begin{array}{c}\text { C-CsZnCr } \\ \text { or } \\ \text { C-CuZnCr }\end{array} & \text { C-CuZnCr } & \text { C-CuZnCr } \\ \begin{array}{l}\text { Run Temperature, }{ }^{\circ} \mathrm{F} \\ \begin{array}{l}\text { Hydrogenated and } \\ \text { Cracked Products, w\% }\end{array}\end{array} & 800 & 750 & 700 & 650 \\ & 43-45 & 30-33 & 19 & 10.8\end{array}$

\section{Liquid Medium: Decalin}

Run Duration, Minutes

Hydrogen Pressure, psig

Catalyst

Run Temperature, ${ }^{\circ} \mathrm{F}$

$\begin{array}{cc}120 & 120 \\ 2000 & 2000 \\ \mathrm{C}-\mathrm{Cu}-\mathrm{ZnCr} & \mathrm{C}-\mathrm{CuZnCr} \\ 700 & 650\end{array}$


The results clearly show that 1-Methyl Naphthalene undergoes considerable cracking and hydrogenation at or above $650^{\circ} \mathrm{F}$ temperature. Decalin does not crack at $650^{\circ} \mathrm{F}$ temperature, and starts cracking at a temperature in the range of $650-700^{\circ} \mathrm{F}$.

Based on these test results, the catalyst activity test runs were conducted at $<700^{\circ} \mathrm{F}$ temperatures using decalin as the liquid medium and carbon-coated cesium-promoted $\mathrm{Cu}$-Zinc-chromite as the SOTA catalyst.

\section{3) Catalyst Activity Test Run 245-60 With Carbon-Coated SOTA Cesium-Promoted Copper-Zinc-Chromite Catalyst}

Catalyst activity testing was conducted in a two stage Robinson Mahoney reactor system (Unit 245) consisting of two stirred 1-liter autoclave reactors with catalyst basket. The basket had cylindrical annular space for catalyst. The catalyst basket in each reactor was initially charged with 80 gms of carbon-coated, Cs-promoted copper-zinc-chromite catalyst. Syn-gas with $\mathrm{H}_{2} / \mathrm{CO}$ ratio of 0.75 and $5 \mathrm{v} \% \mathrm{CO}_{2}$ was used as the feed gas. Decalin (b.p $374^{\circ} \mathrm{F}$ ) was used as the liquid medium. The stirrer speed was kept constant at $1200 \mathrm{rpm}$.

The copper-zinc-chromite catalyst powder, prepared by the usual co-precipitation procedure, had high surface area $\left(94 \mathrm{~m}^{2} / \mathrm{gm}\right)$. The powder was extruded using partially polymerized furfuryl alcohol. Due to high reactivity of the catalyst, we encountered problem in carbonization and oxidation steps for carbon-coating the extrudates. With any contact with air, the extrudates were heating up and oxidizing the coating even at room temperature. After several trials, the carbonization step was optimized by eliminating any possible presence of oxygen. The oxidation step, which opens up the pores and increase the surface area, could not be optimized due to rapid excursion in temperature affecting the catalyst properties. As a result, very limited oxidation of the extrudates was carried out. After $3 \mathrm{w} \%$ cesium impregnation, the catalyst extrudates used in the K-2 reactor had the following properties:

\section{Sample No. $\quad$ Carbon, w\% $\quad$ Surface Area, $\mathrm{m}^{2} / \mathrm{gm}$}

$\begin{array}{lll}\mathrm{Cs}-\mathrm{CCuZnCr} & \mathrm{O}_{3}-011101 & 10.8\end{array}$

The surface area was low due to high carbon content and damage by temperature excursion. Crush strength measurement could not be carried out due to reactivity with air. The catalyst extrudates were introduced in the reactors under nitrogen blanket to avoid any oxidation.

A 144-hour run (24 hours for each period) with two different space velocities was conducted at 1500 psig pressure, $620-680^{\circ} \mathrm{F}$ temperature in the first stage and $640-680^{\circ} \mathrm{F}$ temperature in the second stage. A sketch of the Unit 245 experimental set up is shown in Figure 1. 
Due to low temperature operation, no cracking of decalin was observed. The clear liquid in the reactor at the end of the run had $100 \%$ decalin content. However, there was some loss of decalin during the run most probably due to carry over of decalin vapor in the gaseous stream. There was strong possibility of loosing significant amount of light liquid products in the gaseous stream. In order to avoid the liquid loss problem in the future, the gaseous streams should pass through low temperature condenser (called Chiller using ethylene glycol as coolant).

Table 3 and Table 4 present the operating conditions and results of the run. Due to malfunction of the Gas Chromatography, the GC-analyses of the gaseous products were in significant error. As a result, the $\mathrm{CO}$ conversion and gaseous products yield could not be determined.

The analyses of the light liquid product (0-4 stream) are presented in the tables. Based on liquid product yield alone, the $\mathrm{CO}$ conversion was approximately $5 \mathrm{~V} \%$. Any light liquid product lost in the gaseous stream should increase this conversion number. The elemental analyses show the presence of oxygenated hydrocarbons. The light hydrocarbons were analyzed by outside laboratory showing the presence of 40.7 to $43.9 \mathrm{w} \%$ oxygen.

The Infra-Red analyses for the liquid fractions (IBP- $185^{\circ} \mathrm{F}, 185-250^{\circ} \mathrm{F}, 250^{\circ} \mathrm{F}+$ ) of periods $245-$ 60-1, 245-60-3, 245-60-4, and 245-60-5 show strong peaks at 3200-3650 due to alcohols.

Qualitative GC-MS analyses of the IBP- $185^{\circ} \mathrm{F}$ and $185-250^{\circ} \mathrm{F}$ fractions show the presence of the chemicals which are mostly higher alcohols, acids, and hydrocarbons. For example:

IBP-185 F Fraction------2-methyl-1-Butanol, 2-methyl-1-Propanol, 3-Pentanol, 3-methylPentanoic acid, 2-methyl-2Butene.

$185^{\circ} \mathrm{F}-250^{\circ} \mathrm{F}$ Fraction----2-methyl-1-Butanol, 1-Butanol, 3-methyl Butanoic acid, 1-Pentene, Methyl Butenol, 3-propyl-1-4-pentadiene , 2-methyl-1-Propanol etc.

The spent catalyst from the reactor was toluene extracted and weighed. Result showed that there was no loss of catalyst by attrition. 


\section{Table 3 \\ Catalyst Activity Testing}

\section{RUN 245-60 \\ Carbon-Coated Catalyst in Each Reactor: $80 \mathrm{Gm}$}

\begin{tabular}{|c|c|c|c|c|}
\hline Period & $1 \mathrm{~A}$ & 1B & $2 A$ & 2B \\
\hline Reactor Pressure, psig & 1500 & 1500 & 1500 & 1500 \\
\hline Reactor K-1 Temperature, 으 & 620 & 620 & 620 & 620 \\
\hline Reactor K-2 Temperature, ㅇF & 640 & 640 & 640 & 640 \\
\hline Inlet $\mathrm{H} 2 / \mathrm{CO} / \mathrm{CO}_{2}$ GHSV (I/kg-cat/hr) & 970 & 970 & 988 & 988 \\
\hline Liquid Medium (Decalin) Recycle, Gm/Hr & 50 & 50 & 50 & 50 \\
\hline 0-4 Liquid Product, Gm/Hr & 7.1 & 7.1 & 6.4 & 6.4 \\
\hline \multicolumn{5}{|l|}{$\begin{array}{c}\text { Gaseous Products: } \\
\mathrm{C}_{1}-\mathrm{C}_{3}, \mathrm{~V} \% \\
\mathrm{C}_{4}-\mathrm{C}_{7}, \mathrm{~V} \%\end{array}$} \\
\hline \multicolumn{5}{|l|}{ 0-4 Liquid Product Analyses: } \\
\hline Carbon, wt\% & & 44.85 & & \\
\hline Hydrogen, wt\% & & 11.08 & & \\
\hline Oxygen (By Difference), wt\% & & 44.07 & & \\
\hline IBP- $185^{\circ} \mathrm{F}, \mathrm{V} \%$ & & 89 & & \\
\hline $185-250^{\circ} \mathrm{F}, \mathrm{V} \%$ & & 9 & & \\
\hline $250^{\circ} \mathrm{F}+, \mathrm{V} \%$ & & 2 & & \\
\hline
\end{tabular}


Table 4

\section{Catalyst Activity Testing}

RUN 245-60

\section{Carbon-Coated Catalyst in Each Reactor: 80 Gm}

\begin{tabular}{|c|c|c|c|c|}
\hline Period & 3 & 4 & 5 & 6 \\
\hline Reactor Pressure, psig & 1500 & 1500 & 1500 & 1500 \\
\hline Reactor K-1 Temperature, 으 & 650 & 650 & 680 & 680 \\
\hline Reactor K-2 Temperature, 으 & 660 & 660 & 680 & 680 \\
\hline Inlet $\mathrm{H}_{2} / \mathrm{CO} / \mathrm{CO}_{2} \mathrm{GHSV}(1 / \mathrm{kg}$-cat $/ \mathrm{hr})$ & 988 & 634 & 662 & 662 \\
\hline $\begin{array}{l}\text { Liquid Medium (Decalin) Recycle, } \\
\text { Gm/Hr--------- }\end{array}$ & 50 & 50 & 50 & 50 \\
\hline 0-4 Liquid Product, Gm/Hr & 5.9 & 4.2 & 4.3 & 3.8 \\
\hline \multicolumn{5}{|l|}{$\begin{array}{l}\text { Gaseous Products: } \\
\qquad \begin{array}{c}\mathrm{C}_{1}-\mathrm{C}_{3}, \mathrm{~V} \% \\
\mathrm{C}_{4}-\mathrm{C}_{7}, \mathrm{~V} \%\end{array}\end{array}$} \\
\hline \multicolumn{5}{|l|}{ 0-4 Liquid Product Analyses: } \\
\hline $\begin{array}{l}\text { Carbon, wt } \% \\
\text { Hydrogen, wt\% } \\
\text { Oxygen(By Difference), wt } \%\end{array}$ & $\begin{array}{l}44.85 \\
11.08 \\
44.07\end{array}$ & $\begin{array}{r}48.9 \\
11.75 \\
39.35\end{array}$ & $\begin{array}{r}48.9 \\
11.75 \\
39.35\end{array}$ & \\
\hline $\begin{array}{l}\text { IBP-185으, V\% } \\
185-250^{\circ} \mathrm{F}, \mathrm{V} \% \\
250^{\circ} \mathrm{F}+\mathrm{V} \%\end{array}$ & $\begin{array}{r}89 \\
9 \\
2\end{array}$ & $\begin{array}{r}74 \\
17 \\
9\end{array}$ & $\begin{array}{r}74 \\
17 \\
9\end{array}$ & \\
\hline
\end{tabular}




\section{4) Catalyst Activity Test Run 245-64 With Carbon-Coated SOTA Cesium-Promoted Copper-Zinc-Chromite Catalyst}

Catalyst activity testing was conducted in ebullated bed mode in a two stage Robinson Mahoney reactor system (Unit 245) consisting of two stirred 1-liter autoclave reactors with catalyst basket. Because of ebullated bed mode, the catalyst basket inside each reactor had metal wall on the side and 24-mesh size screen opening at the top and bottom. The stirrer speed maintained the fluid flow inside each reactor and the catalyst basket. The catalyst basket in each reactor was charged with 75 gms of carbon-coated, Cs-promoted copper-zinc-chromite catalyst. The catalyst extrudates had the following properties:

$\begin{array}{lcccc}\text { Sample No. } & \begin{array}{c}\text { Extrudate } \\ \text { Diameter, } \mathbf{~ m m}\end{array} & \begin{array}{c}\text { Crush } \\ \text { Strength, lb/mm }\end{array} & \begin{array}{c}\text { Surface } \\ \text { Area, } \mathbf{~ m}^{2} / \mathbf{g m}\end{array} & \begin{array}{c}\text { Carbon, w\% } \\ \mathrm{CCsCuZnOCr}{ }_{2} \mathrm{O}_{3}-71001 \mathrm{SB}\end{array} \\ 0.7 & 2.7 & 89 & 16.9\end{array}$

Syn-gas with $\mathrm{H}_{2} / \mathrm{CO}$ ratio of 0.75 and $5 \mathrm{v} \% \mathrm{CO}_{2}$ was used as the feed gas. Decalin (b.p $374^{\circ} \mathrm{F}$ ) was used as the liquid medium. The catalyst in the reactor was pretreated with hydrogen flow at 1000 psig pressure at $360^{\circ} \mathrm{F}$ temperature and $1200 \mathrm{rpm}$ stirrer speed for 14 hours.

An overall 170-hour run (24 hours for each period) with five different space velocities was conducted at $1500-1700$ psig pressure, $570-650^{\circ} \mathrm{F}$ temperature in the first stage and $520-685^{\circ} \mathrm{F}$ temperature in the second stage. A sketch of the Unit 245 experimental set up is shown in Figure 1. The condensers at $0-4$ and $0-5$ were equipped with ethylene glycol as coolant to maintain low temperatures in order to avoid loss of liquids. The stirrer speed varied between 1000 to $1500 \mathrm{rpm}$.

Table 5 and Table 6 present the operating conditions and results of the run. The $\mathrm{H}_{2} / \mathrm{CO} / \mathrm{CO}_{2}$ GHSV (gas-hourly-space-velocity) varied between 640 to 2535 liter $/ \mathrm{kg}$-catalyst/hr. The liquid alcohol product yields are presented. The outlet gas flow rates and the $\mathrm{GC}$ analysis of the product gases were not reliable. Consequently, the $\mathrm{CO}$ conversion rates are not reported. Also the $\mathrm{C}_{1}-\mathrm{C}_{3}$ gas flow rates are not quantitative.

The $\mathrm{C}_{2}-\mathrm{C}_{6}$ alcohol product distribution for the Period 7A (12 hours) is as follows:

$\begin{array}{lc}\text { Ethanol, w\% } & 17.8 \\ \text { 1-Propanol, w\% } & 31.9 \\ \text { 2-methyl 1-propanol, w\% } & 37.7 \\ \text { 1-Butanol, w\% } & 6.6 \\ \text { 2-methyl 1-Butanol, w\% } & 6.0\end{array}$

The $\mathrm{C}_{2}-\mathrm{C}_{6}$ alcohol production rates in $\mathrm{gm} / \mathrm{kg}$-cat $/ \mathrm{hr}$ for this run were compared with those for the DOE pilot plant run at LaPorte, Texas using slurry phase reactor. (Reference: Heydopn, E.C. et al, Proc. Coal Liquefaction and Gas Conversion Contractors' Review Conf., U.S. Dept. of Energy - PETC, Pittsburgh, PA. 293, 1994). 
Figures 2-4 show the $\mathrm{C}_{2}-\mathrm{C}_{6}$ alcohol and methanol production rates as points in periods 3,5 and 7A of the Run 245-64 in simulated ebullated bed mode. The DOE results are also plotted in these figures for comparison purpose. Recycle of light alcohol in the DOE run resulted in three fold increase in $\mathrm{C}_{2}-\mathrm{C}_{6}$ alcohol production rate. Although no light alcohol was recycled in Run 245-64, similar increase in $\mathrm{C}_{2}-\mathrm{C}_{6}$ alcohol production rate as in the DOE run is expected.

Since the Run 245-64 was a simulated ebullated bed operation in Robinson-Mahoney reactor using catalyst basket and stirrer, the alcohol production rates in Run 245-64 were multiplied by an equivalent catalyst-contact-time factor for proper comparison. The DOE run had $40 \mathrm{~V} \%$ catalyst in the slurry phase reactor. In Run 245-64, the catalyst in the reactor was $10 \mathrm{~V} \%$ and the catalyst was restricted in the catalyst basket only. As a result, in this run syngas had much less contact time with the catalyst. The catalyst contact time factor used is 4 , although it should be higher than 4. The overall results show that at 1500 psig pressure, the $\mathrm{C}_{2}-\mathrm{C}_{6}$ alcohol production rates in Run 245-64 are close to those for the DOE run. At 1700 psig pressure, the $\mathrm{C}_{2}-\mathrm{C}_{6}$ alcohol production rate increased significantly for the carbon-coated catalyst Run 245-64. At 1750 psig pressure in DOE run, the $\mathrm{C}_{2}-\mathrm{C}_{6}$ alcohol production increase was not so high.

At usual 2000 psig pressure operation, high rate of $\mathrm{C}_{2}-\mathrm{C}_{6}$ alcohol production is expected for processes using carbon-coated SOTA or Advanced catalysts.

\section{Catalyst Recovery}

The Run 245-64 was in a simulated ebullated bed operation mode using a stirrer and a catalyst basket with 24-mesh screen at the top and bottom for fluid flow. The ebullation of the catalyst particles in the basket depends upon the stirrer speed, the catalyst size and catalyst density. Proper stirrer speed is very important because low speed may have insufficient ebullation whereas high speed can crush the catalyst extrudates by hitting the basket wall.

Catalyst loss in the reactor K-1 was $<3 \mathrm{w} \%$ which is on the low side for ebullated bed operation for 170 hours using commercial catalyst. However, our carbon-coated catalyst should have much lower loss as demonstrated in the earlier Runs 245-59 and 245-60, although annular catalyst basket was used for these two runs. It appears that the stirrer speed of 1200 to $1500 \mathrm{rpm}$ used in this simulated ebullated Run 245-64 was quite excessive and contributed to damage of the catalyst particles. The recovered catalyst particles have sufficient crush strength $(1.85 \mathrm{lb} / \mathrm{mm})$ for actual ebullated bed operation to have low attrition loss.

Cold flow testing with 1/16 inch commercial catalyst extrudates show the proper stirrer speed is approximately $1200 \mathrm{rpm}$. For our 1/40 inch carbon-coated catalyst extrudates with lower density, the proper stirrer speed for ebullation should be much less than $1200 \mathrm{rpm}$, presumably less than $900 \mathrm{rpm}$. In the future, we plan to test for the proper stirrer speed needed for our carbon-coated catalysts.

Catalyst loss in reactor K-2 was $\sim 22 \mathrm{w} \%$ which is too high for 170 hours of ebullated bed operation for catalyst extrudates with initial crush strength of $2.7 \mathrm{lb} / \mathrm{mm}$. Again the excessive stirrer speed in this simulated ebullated bed operation appears to be the cause for the high loss of catalyst in this reactor. In actual ebullated bed operation, low attrition loss is expected. 


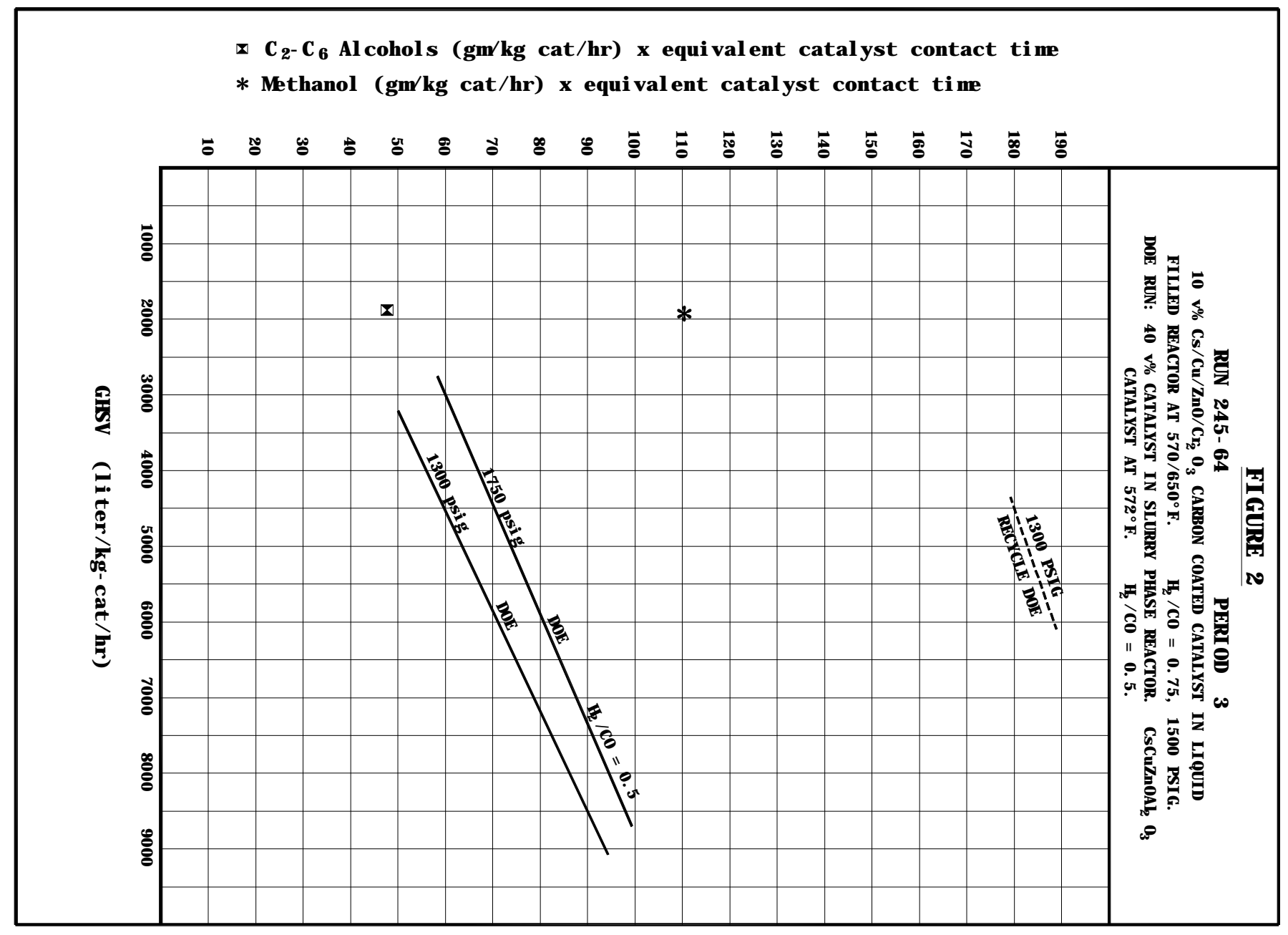




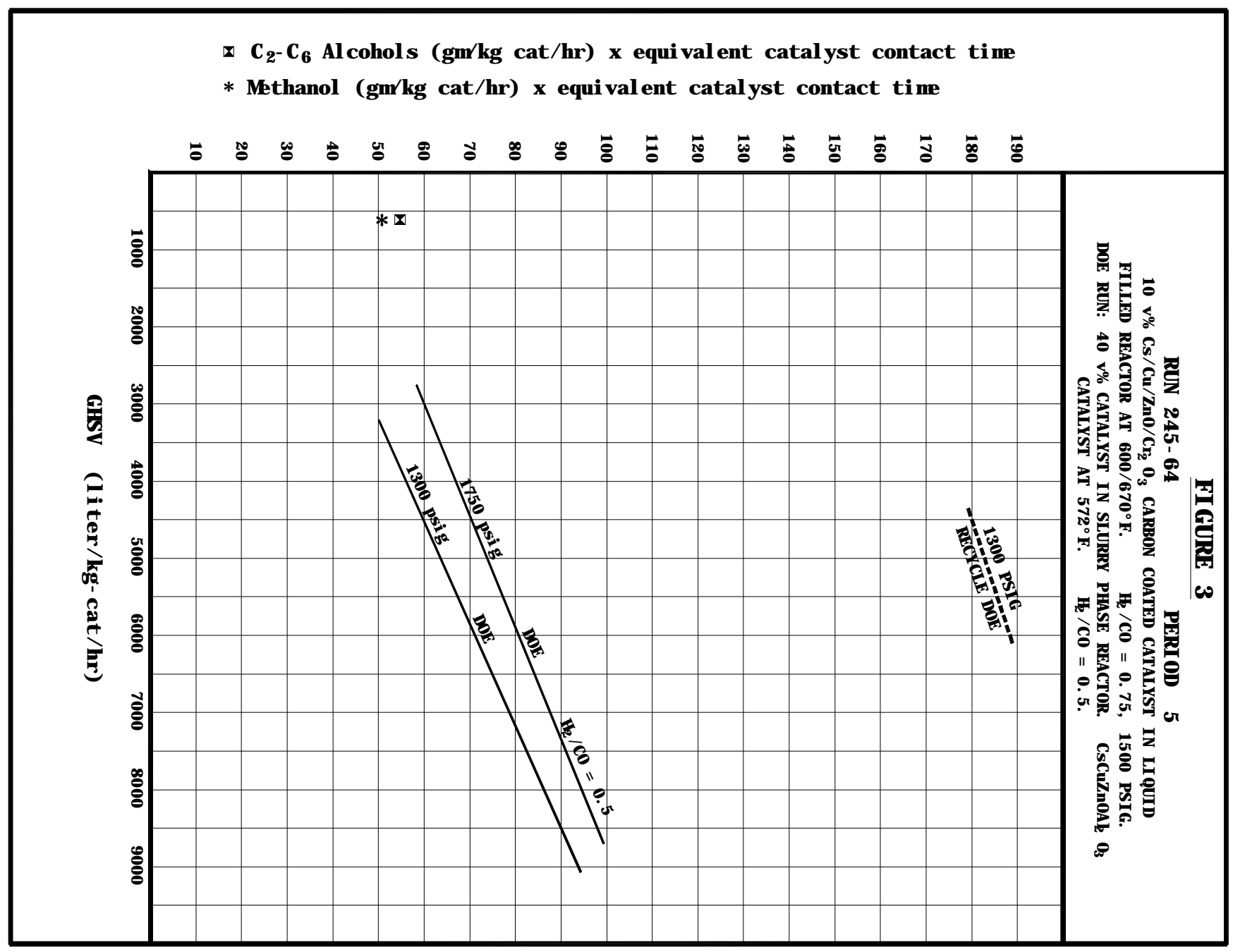




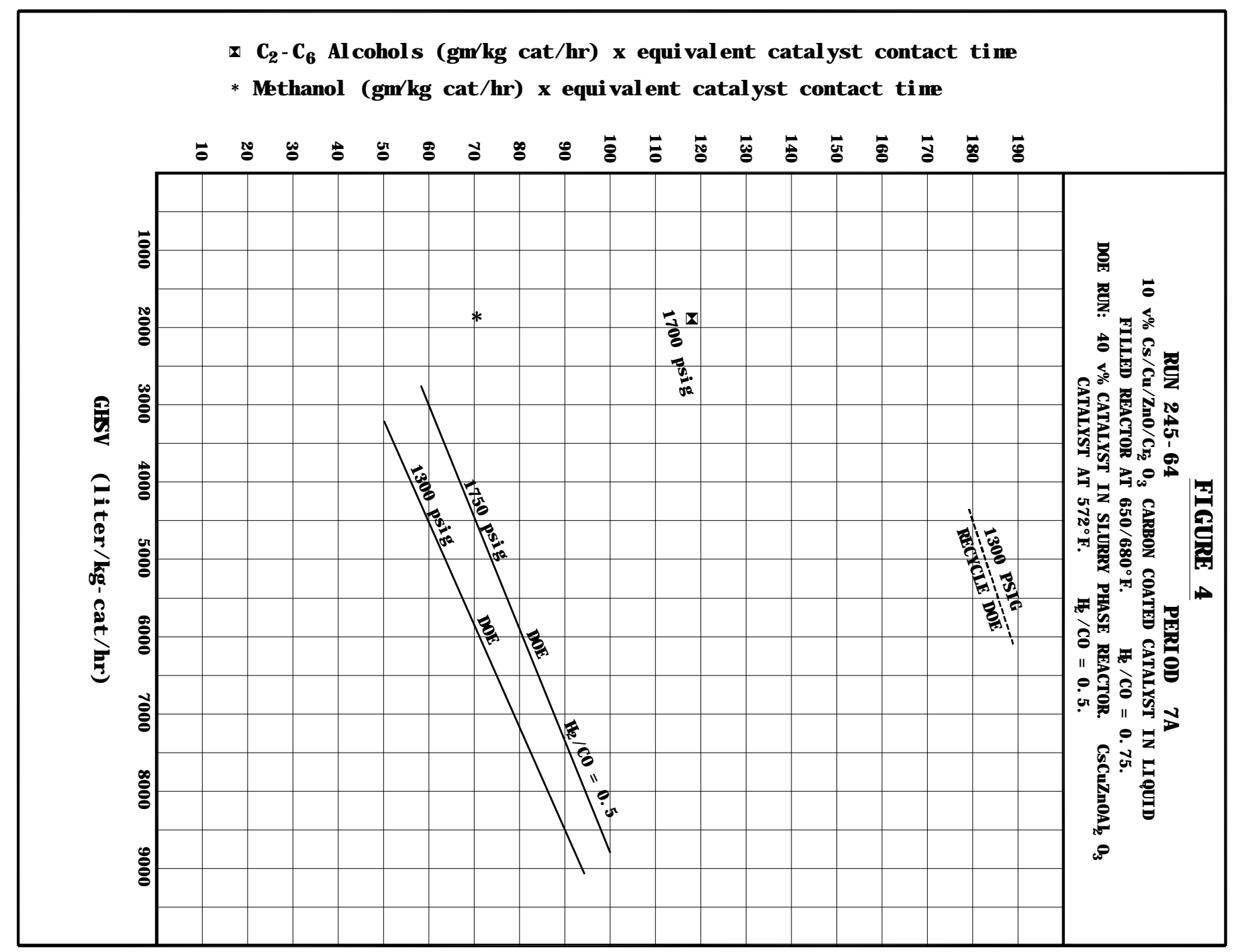




\section{Table 5 \\ Catalyst Activity Testing}

\section{RUN 245-64 \\ Carbon-Coated Catalyst in Each Reactor: 75 Gm}

\begin{tabular}{|c|c|c|c|c|}
\hline Period & 1 & 2 & 3 & 4 \\
\hline Reactor Pressure, psig & 1500 & 1500 & 1500 & 1500 \\
\hline Reactor K-1 Temperature, 으 & 570 & 570 & 595 & 620 \\
\hline Reactor K-2 Temperature, ${ }^{\circ} \mathrm{F}$ & 570 & 520 & 635 & 640 \\
\hline Inlet $\mathrm{H}_{2} / \mathrm{CO} / \mathrm{CO}_{2}$, GHSV (I/kg-cat $\left./ \mathrm{hr}\right)$ & 2535 & 1266 & 1,900 & 1266 \\
\hline Stirrer Speed, rpm & 1200 & 1200 & 1,500 & 500 \\
\hline 0-4 Liquid Alcohol Product, Gms/hr & 11.6 & 5.92 & 9.17 & \\
\hline
\end{tabular}


Table 6

Catalyst Activity Testing

RUN 245-64

Carbon-Coated Catalyst in Each Reactor: 75 Gm

Period

Reactor Pressure, psig

Reactor K-1 Temperature, $\stackrel{\circ}{-}$

Reactor K-2 Temperature, ${ }^{\circ} \mathrm{F}$

Inlet $\mathrm{H}_{2} / \mathrm{CO} / \mathrm{CO}_{2}$ GHSV (I/kg-cat/hr)

Stirrer Speed, Rpm-------

0-4 Liquid Alcohol Product, Gms/hr
5

1500

600

660

640

1200

4.42
4.63

7A

1700

650

680

1815

$1000 \quad 1000$

7.1 


\section{Task IV: Large Scale Process For Carbon Coated Catalyst Production}

The procedure for preparing carbon coated catalyst consists of four steps:

i) Mixing of catalyst powder and liquid p olymer;

ii) Carbonous extrusion of the mixture;

iii) Carbonization of the extrudates;

iv) Partial oxidation of the extrudates.

In scaling up the procedure to a large scale process, the carbonous extrusion step is most critical. Tests were conducted in batch mode to determine a fast extrusion process using cylinder -piston type extruder with $0.7 \mathrm{~mm}$ diameter holes. Results showed that using this extruder and optimum consistency of the mixture, the extrusion process is fast. The process can be scaled up to a continuous high rate process using a large two-sided extruder. Alternatively, a screw feeder with large extruder plate at the end can also be utilized for fast extrusion process.

It was observed that a mixture of heavy liquid polymer and light liquid polymer provides optimum consistency of the powder-polymer mixture for fast extrusion. The properties of the final carbon coated catalysts were acceptable.

The optimum ratio of heavy-polymer to light-polymer utilized for carbonous extrusion was 1:1. The heavy-polymer was the furfuryl alcohol partially polymerized by sulfuric acid treatment. The light-polymer was furfuryl alcohol partially polymerized by boiling for six hours. The optimum ratio of $\mathrm{Cu}-\mathrm{ZnO}-\mathrm{Cr}_{2} \mathrm{O}_{3}$ catalyst powder to polymer mixture was 1:0.8.

The powder-polymer mixing step can be scaled up using conventional mixers. The steps for carbonization and partial oxidation of the extrudates can be scaled up to continuous process using rotary kilns.

Based on the above discussion, the production process for carbon-coated catalysts is depicted in Figure 5. The extrusion process is made continuous by reciprocating motion of the piston in the extrusion cylinder having extrusion plates at both ends; also the powder -polymer mixture is fed to the extruder cylinder at the two sides of the piston using two screw feeders. Rotary kilns with proper gas flows and temperature control can be used for scaled up continuous carbonization and partial oxidation processes.

To simulate scale up, the carbonization step was carried out in a reactor submerged in a heated sand bath with temperature control. Small to large size reactors for carbonization or oxidation can be utilized in this set up. However, this particular sand bath has a maximum temperature limit of $930^{\circ} \mathrm{F}$. Carbonous catalyst extrudates were carbonized in the sand bath set -up at $800^{\circ} \mathrm{F}$ and in the current tube furnace set-up at $1360^{\circ} \mathrm{F}$ for comparison purpose. The following table presents the key properties of these extrudates for comparison. 


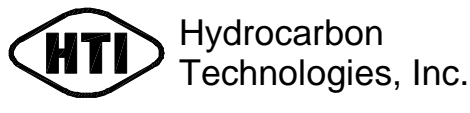

Figure 5

Flowsheet for Carbonous Catalyst Particles Production Process

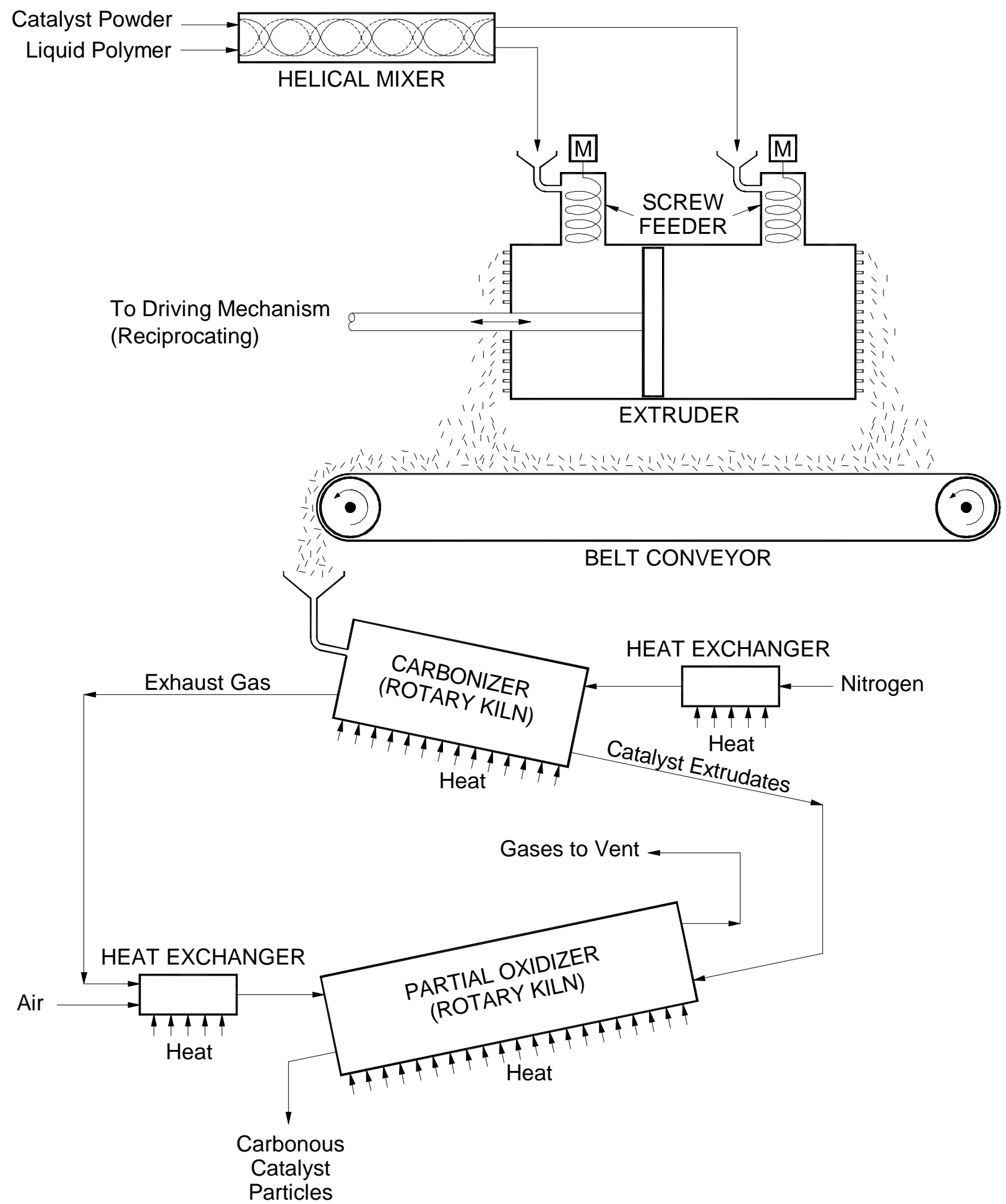


$\mathrm{CuZnOCr}_{2} \mathrm{O}_{3}$ Extrudate

1) Carbonized in Sand Bath Set-Up

2) Sample \#1 partially oxidized

3) Carbonized in Tube Furnace Set -Up

4) Sample \#3 partially oxidized

4) Second coating of Sample \#4 and carbonization in Tube Furnace

6) Partial Oxidation of Sample \#5
Crush Strength, Surface Area, Carbon, w\%

$\mathbf{L b} / \mathbf{m m}$

$\mathbf{m}^{2} / \mathbf{g m} \quad$ Sample \#

1.29

87.9

14.3

1.37

1.22

118.2

13.1

1.29

128.6

2.56

2.75
88

These results show that the properties of the extrudates processed in the Sand Bath set-up are as good as those processed in the small scale Tube Furnace set-up. Also, second coating of the carbonous extrudates provides carbon coated catalyst extrudates with sufficient crush strength.

\section{Task VI: Cost Estimation}

Based on the proposed large scale production process described under Task IV, a cost estimation was carried out for the carbonous extrusion and carbon-coating component in the production of carbon-coated copper-zinc-chromite catalyst extrudates. The cost of the copper-zinc-chromite catalyst powder was not included in this estimate. The cost of the powder is less than $\$ 4$ per pound.

Basis for the estimation was the production of 10,000 pound of catalyst extrudates per week for 48 weeks in a year period. The various cost numbers obtained are described in the following section. 


\section{Basis: 240 tons/yr of Carbon-Coated Catalyst Extrudates (Carbon-free Basis)}

\section{Direct Costs:}

Purchased Equipment Cost

Direct Installation Cost

Total Direct Cost

Indirect Costs (Installation)

Total Capital Investment, TCI
$\$ 778,800$

233,640

$\$ 1,012,440$

241,460

$\$ 1,254,000$

\section{Annual Costs:}

Operating Labor - 2080 man-hr @ \$30/hr

62,400

Maintenance Materials \& Labor

8,000

Electricity

52,000

Air \& Nitrogen

Chemicals (FFA @ $\$ 0.70$ per pound)

10,000

Total Direct Annual O\&M Costs

Total Indirect Annual O\&M Costs

Total Annual O\&M Costs

$\$ 468,400$

92,400

$\$ 560,800$

\section{Annualized Costs:}

Expected Lifetime of Equipments, years

10

Interest Rate, \%

10

Capital Recovery Factor

Annualized Capital Investment Cost ( 0.1627 x TCI)

Total Annual O\&M Costs

Total Annualized Costs
0.1627

$\$ 204,000$

560,800

$\$ 764,800$

Carbon-Coating Cost Per Pound of Catalyst Extrudates, $\$ / 1 b$

So the cost of carbon-coated copper-zinc-chromite catalyst extrudates will be $\$ 1.59$ plus the cost of the catalyst powder. The cost of the powder is less than $\$ 4.00$ per pound. So the total cost of carbon-coated copper-zinc-chromite catalyst extrudates is less than $\$ 5.60$ per pound.

The current market price for 1/4" diameter zinc -chromite catalyst extrudates in large scale from Engelhard Corporation is $\$ 12.7$ per pound.

From the comparison of these numbers, it is obvious that the cost of carbonous extrusion and carbon-coating is highly competitive in the market of catalyst extrudates. 


\section{CONCLUSION}

The following conclusions can be reached based on the accomplishments in the second year of the R\&D program:

1) Carbon-coated SOTA cesium-copper-zinc-chromite catalyst extrudates were successfully prepared and tested for activity studies in a Robinson-Mahoney reactor with catalyst basket using decalin as the liquid medium. The $\mathrm{C}_{2}-\mathrm{C}_{6}$ alcohol production rates were either comparable or superior to earlier DOE pilot plant run using similar catalysts in a slurry phase reactor. By increasing the operating pressure from 1500 psig to $1700 \mathrm{psig}$, the $\mathrm{C}_{2}-\mathrm{C}_{6}$ alcohol production rate increased significantly for the carbon -coated SOTA catalyst. Ebullated bed test runs at 2,000 psig using carbon-coated SOTA and Advanced catalysts are recommended to determine high apparent potential of these catalysts towards commercial applications.

2) The carbonous extrusion step, the key step in carbon-coated catalyst preparation, was developed for continuous large scale production.

3a) A continuous process for producing carbonous catalyst extrudates was proposed.

3b) A cost estimation based on the proposed production process show the cost of carbon-coated catalyst production is $\sim \$ 1.59$ per pound of catalyst extrudates (excluding the cost of catalyst powder). This low cost makes the carbon-coated catalyst extrudates highly competitive in the catalyst extrudate market.

\section{FURTHER WORK PLANNED}

The following is a list of the planned further work to complete the proposed R\&D program.

1. Actual ebullated bed run at $\geq 2000$ psig pressure using carbon-coated SOTA catalyst and syngas.

2. Actual ebullated bed run at $\geq 2000$ psig pressure using carbon-coated Advanced catalyst and syngas.

3. Economic assessment of the process and technology of carbon-coated catalyst in ebullated bed reactor. 